\title{
VIGILÂNCIA ELETRÔNICA NO ESPAÇO ESCOLAR E SUAS IMPLICAÇÕES NO PROCESSO DE ENSINO E APRENDIZAGEM
}

\section{ARTIGO ORIGINAL}

FILHO, Hénel Francisco Lopes da Silva ${ }^{1}$

FILHO, Hénel Francisco Lopes da Silva. Vigilância eletrônica no espaço escolar e suas implicações no processo de ensino e aprendizagem. Revista Científica Multidisciplinar Núcleo do Conhecimento. Ano 04, Ed. 08, Vol. 06, pp. 55-71. Agosto de 2019. ISSN: 2448-0959

\section{RESUMO}

A vigilância empregada no espaço escolar, presente desde a formação das primeiras salas de aula e atualmente se disseminando na forma eletrônica, é considerada, por muitos especialistas, como um instrumento que influencia nas ações de alunos e professores. Autores que tratam dessa questão demonstram que as mudanças de ações, quando diante das câmeras, decorrem da capacidade que este instrumento de vigilância possui de provocar uma maior sensação de segurança, comprometendo a privacidade e espontaneidade necessárias no processo de ensino/aprendizagem e, sobretudo, de exercer um controle disciplinar daqueles que se encontram na condição de vigiados. Diante disso, o presente trabalho foi elaborado com o objetivo de discutir a influência que o dispositivo de vigilância pode exercer nas ações de professores e alunos presentes no espaço escolar, levando em conta aspectos como segurança, privacidade e controle disciplinar. A abordagem metodológica partiu de uma revisão bibliográfica sobre o tema, enriquecida com publicações em revistas da área de educação. Por se tratar de um tema controverso, a pesquisa alerta para a necessidade

\footnotetext{
${ }^{1}$ Mestre em Ciências da Educação pela Universidad Interamericana Del Paraguay. Pós-Graduado em Vigilância Sanitária pela Faculdade São Camilo - Salvador/Bahia. Pós-Graduado em Gestão Ambiental pela Fundesp - Bahia. Graduado em Ciências Biológicas pela UCSAL/Bahia.
} 
de debates que venham a contribuir para o melhor uso desse equipamento no ambiente escolar.

Palavras-chave: Câmeras de vigilância, sala de aula, segurança, privacidade, controle disciplinar.

\section{INTRODUÇÃO}

Assim como ocorre com as novas tecnologias de informação e comunicação, vamos dando conta que as câmeras de vigilância estão se tornando cada vez mais uma ferramenta eletrônica integrante do cotidiano das escolas. Multiplicando-se em uma progressão geométrica, representam, sem dúvida, o principal mecanismo de vigilância que está sendo largamente utilizado nesses espaços (MELGAÇO, 2012).

A adoção dos instrumentos de vigilância eletrônica no espaço escolar tem sido justificada por questões de segurança, tendo em vista os acontecimentos violentos que vão se tornando cada vez mais comuns nesse ambiente. Tais acontecimentos, intensamente explorados pela mídia, fazem aumentar a sensação de intranquilidade de alunos e professores, prejudicando o desenvolvimento de suas atividades de rotina.

O que se espera, quando se utiliza um mecanismo de vigilância eletrônica, é que este instrumento seja capaz de gerar um ambiente mais seguro, ordenado e previsível. Seu olhar coíbe os indivíduos a praticarem ações que se desviem das normas aplicadas naquele espaço. Conduz a uma uniformização das ações, reduzindo a possibilidade do imprevisto, afastando o medo, garantindo um local ordenado, racional, um "futuro desejado", onde as relações sociais são favorecidas (CASTRO et PEDRO, 2010).

Ocorre que, uma vez posicionados em pontos estratégicos da escola, especificamente as salas de aula, tais equipamentos começam a projetar seus olhares técnicos e impessoais a professores e estudantes ali presentes. A possibilidade de estar sendo vigiado faz com que os indivíduos se tornem auto vigilantes dos seus próprios atos, passando a adotar comportamentos diferentes. Acredita-se, então, que "ligadas ou não, as câmeras estão lá, e sua função é indicar um código comportamental em um determinado espaço" (FIRMINO, 2010, p.100). 
De acordo com Foucault (2014), os sistemas de vigilância dos tempos atuais realizam o mesmo papel do dispositivo panóptico das instituições disciplinares de séculos passados, funcionando como um instrumento para vigiar e controlar a disciplina. Favorecem o adestramento dos alunos, transformando-os em indivíduos dóceis e úteis, uma vez que o olhar que vigia faz desencadear um processo de interiorização no vigiado, a ponto de ele observar e exercer a vigilância sobre si mesmo.

Além dessa implicação, é comumente discutido como grande prejuízo causado pela presença da câmera de vigilância, o fato desse instrumento representa ruma invasão à privacidade dos indivíduos, interferindo na espontaneidade de suas ações. Acreditase que seu olhar intrusivo incomoda, viola o respeito, gera angústia, aumenta o medo e a vulnerabilidade. (LEMOS, 2010).

Para outros, no entanto, a presença da câmera no ambiente escolar, utilizada para fins de segurança, pode não significar necessariamente prejuízos à privacidade. A sociedade atual, extremamente vigiada e controlada, redefine a cada instante a percepção para o que é público e privado. Bauman (2014) argumenta que o que antes era considerado invisível, relacionado à intimidade e a vida interior de cada um, hoje deve ser exposto ao público.

\section{EVOLUÇÃO DA VIGILÂNCIA NO ESPAÇO ESCOLAR}

Há séculos passados, o ensino nas escolas dos países do continente europeu ocorria de forma individualizada. Cada aluno permanecia alguns instantes com o professor, enquanto os demais, de forma aglomerada e sem vigilância, esperavam ociosos o momento de serem atendidos. (FOUCAULT, 2014, p.144).

De acordo com Araújo (2010), somente a partir do século XVI iniciou-se a organização escolar em classes, aplicando-se o princípio de ensinar a um grande número de alunos de forma simultânea. No século seguinte, formaram-se as escolas populares, abrigando crianças de classe social menos favorecida e distribuindo-as em diferentes níveis de ensino, levando em consideração suas idades e graus de conhecimento. Nestes espaços, educadores ensinavam e exerciam, ao mesmo tempo, uma vigilância e disciplinas de forma rígida. 
No final do século XVIII até meados do século XIX predominava, nos países europeus, o ensino mútuo ou monitorial. Praticado dentro de um espaço retangular, monitores aplicavam as lições a grupos de alunos distribuídos em carteiras coletivas e dispostas em filas paralelas. Surgiam, assim, as relações de poder e hierarquia entre professores, monitores e alunos, transformando, as instituições disciplinares, semelhantes a verdadeiros presídio, em

fábricas de ordem, onde prevaleciam as situações previsíveis e, por conseguinte, controláveis. Empreendiam a tarefa de estabelecer a ordem mais ou menos do mesmo modo: colocavam os pupilos sob a mira do supervisor e diretor, de quem se esperava que punisse as más ações e recompensasse as boas; todas elas expunham os pupilos a pressões e estímulos cuidadosamente escolhidos, ao mesmo tempo em que tentavam com empenho neutralizar todas as outras influencias não planejadas e desintegradoras, na esperança de que resultasse na uniformidade da conduta dos pupilos (BAUMAN, 1998, p.163).

No final do século XVIII e perdurando até o início do século XX as instituições europeias caracterizavam-se por apresentar um desenho arquitetônico baseado na vigilância panóptica (explicar rodapé). Esse mecanismo de vigilância fazia "induzir no individuo um estado de consciência e permanente de visibilidade, onde ele nunca deveria saber se estava sendo vigiado, mas deveria ter certeza que sempre poderia sê-lo" (FOUCAULT, 2014, p. 192).

Por meio do autocontrole dos vigiados, esse mecanismo de vigilância cumpria a função de disciplinar a muitos de forma eficiente, resultando em uma aglomeração útil e produtiva. Ao mesmo tempo, permitia efetuar o controle das ações sociais, acarretando o fortalecimento do poder.

Diante do exposto, podemos perceber que a vigilância no espaço escolar, originada há séculos, continua presente na educação contemporânea. Os mecanismos de vigilância apenas se aperfeiçoaram ao longo dos tempos, possibilitando acompanhar as transformações ocorridas na sociedade. Com a crescente inserção da tecnologia no cotidiano das pessoas, passamos agora a ficar no espaço escolar, cenário de 
constantes atos de indisciplina e violência, sob o foco do olhar vigilante instrumentalizado.

Por meio deste recurso tecnológico, os comportamentos e ações dos vigiados passam a ser minimamente observados. Em decorrência disso, podem ser geradas novas formas de comportamento e relacionamento entre as pessoas. Decerto, a presença da vigilância eletrônica e o poder do seu olhar influenciam, de alguma maneira, as ações individuais e a dinâmica das relações interpessoais que ocorrem no espaço escolar.

\section{CÂMERA DE VIGILÂNCIA NO ESPAÇO ESCOLAR: UM INSTRUMENTO DE CONTROLE DISCIPLINAR}

A vigilância eletrônica, característica básica do mundo moderno, tem se difundido silenciosamente ano após ano. Mais precisamente a partir da última década do século passado, inicia-se uma substancial expansão da vigilância por meios eletrônicos em escala global. Essa expansão, ocorrida por todo mundo social e claramente perceptível no Brasil e demais países que se encontram em processo de franco desenvolvimento, termina por invadir a vida das pessoas em prol da formação de espaços supostamente mais seguros. (BAUMAN, 2014, p.17).

Segundo Batista (2013), a crescente busca pela implantação dos dispositivos de vigilância nos espaços urbanos das grandes cidades brasileiras está relacionada, dentre outros aspectos, à qualidade dos serviços que as instituições públicas oferecem aos cidadãos. Para a autora, os órgãos governamentais que têm o papel de proporcionar segurança aos cidadãos não existem ou encontram-se sucateados. O serviço prestado de forma lenta, burocrática e impregnado de corrupção, termina prejudicando a população que, sentindo-se desprotegida, termina recorrendo aos dispositivos de vigilância eletrônica para aumentar a segurança nos locais onde vivem e trabalham.

No caso das escolas, a implantação dos dispositivos de vigilância tem se justificado unicamente pela necessidade de aumentar a segurança nesse espaço. Preservar a segurança no meio em que vivemos sempre foi uma das metas prioritárias dos cidadãos. Decerto, "a segurança não é um valor de que estamos dispostos a abrir RC: 35932

Disponível em: https://www.nucleodoconhecimento.com.br/educacao/vigilancia-eletronica 
mão, e ao que tudo indica, a vigilância é uma das iniciativas capazes de trazer esse alento" (CASTRO e PEDRO, 2010, p.51).

Estamos vivendo em uma verdadeira "atmosfera do medo ambiente" (BAUMAN, 1998, p. 33). Sem dúvida, os espaços urbanos, incluindo as escolas, tem revelado um cenário insustentável de insegurança e medo, onde são praticados diferentes tipos de violência. Esse cenário atual, que favorece a rápida expansão dos mecanismos de vigilância eletrônica, é também exposto por Abramovay, Avancini e Oliveira (2017), quando explicam que

com o passar do tempo, a violência escolar foi ganhando traços mais graves e transformando-se em um problema social realmente preocupante. Hoje, relaciona-se com a disseminação do uso de drogas, o movimento de formação de gangues - eventualmente ligadas ao narcotráfico - e com a facilidade de portar armas, inclusive as de fogo. Tudo isso tendo como pano de fundo o fato de que as escolas perderam o vínculo com a comunidade e acabaram incorporadas à violência cotidiana do espaço urbano. Enfim, deixaram de ser o porto seguro para os jovens estudantes (ABRAMOVAY, M.; AVANCINI, M.; OLIVEIRA, H; 2017, p. 30)

Nesse aspecto, Teixeira e Porto (1998) afirmam que o crescente nível de violência nos centros urbanos transpõe os muros da instituição escolar e se alastra por todos os seus espaços internos. Rocha (2008), também ressalta que "a escola acaba por se transformar na arena de muitos conflitos presentes na localidade. As disputas de território pelos traficantes, algumas vezes, explodem dentro da escola" (ROCHA, 2008, p. 201). Para o autor, essa reprodução explícita da violência nas áreas internas da escola alimenta o sentimento de insegurança e medo das pessoas que se utilizam deste espaço.

Tendo como foco as ações violentas ocorridas dentro do estabelecimento escolar, inúmeras reportagens em diferentes meios de comunicação nos fazem perceber que atos de vandalismo, assédio sexual, bullying, agressões físicas, prática de roubo e outros estão se tornando cada vez mais rotineiros. Diante disso, "os professores, 
atemorizados, se veem impotentes para reverter a situação e restabelecer a ordem" (MARRA e TOSTA, 2008, p. 176).

Há um entendimento geral de que a tarefa de ensinar vem se tornando cada vez mais difícil de ser executada pelos profissionais de educação. Para Abramovay, Avancini e Oliveira (2017), situações de indisciplina e violência em sala de aula revelam a crise da autoridade docente. Admite a autora que o atual clima de insegurança existente no ambiente escolar, "fragiliza a autoridade dos responsáveis pela ordem na escola a tal ponto que ficam imóveis, com receio de sofrer represálias"(ABRAMOVAY, M; AVANCINI, M.; OLIVEIRA, H.; 2017, p. 32-33).

Neste cenário de indisciplina e violência escolar, importa chamar a atenção para a dificuldade de estabelecer definições mais precisas sobre estes dois termos. Diante dessa imprecisão semântica, Silva e Nogueira (2008) afirmam que a indisciplina deve ser entendida como uma negação às regras exclusivamente pedagógicas criadas pela unidade escolar, e quando não cumpridas, causariam uma perturbação ao processo de ensino e aprendizagem, enquanto os atos de violência seriam aqueles que configurariam como criminosos, previstos no Código Penal.

Embora reconheça a dificuldade de estipular uma conceituação que possa delimitar de forma precisa o que seria atos de indisciplina e o que abrange apenas atos de violência, Silva e Nogueira (2008) relatam que, de uma forma geral, os estudos recentes consideram a

indisciplina apenas aqueles comportamentos que violam mais diretamente as regras criadas estritamente com vistas à garantia das condições necessárias à realização do trabalho pedagógico. Isso certamente inclui alguns comportamentos que violam regras sociais mais gerais, de fundo ético-social, que servem para regular a convivência entre os sujeitos no ambiente escolar, mas que não chegam a atingir o foro da violência. Acreditamos que esse foro só é atingido quando se observa nos comportamentos uma intenção de causar danos materiais aos sujeitos ou uma certa capacidade de atingi-los em sua integridade física, psicológica ou moral (SILVA e NOGUEIRA, 2008, p. 33). 
Considerando exclusivamente os atos violentos, vale salientar que as ameaças feitas pelos alunos aos professores, sejam estas presenciadas, relatadas ou noticiadas, vão tomando uma dimensão cada vez maior, tornando-se muito frequentes durante a prática pedagógica. Em pesquisa ${ }^{[2]}$ realizada a nível nacional, foi constatado que a maioria dessas ameaças, não raramente, resulta em agressão física, o que gera um clima de tensão cotidiana, aumentando o sentimento de insegurança de todos aqueles que frequentam o espaço escolar.

Portanto, tais situações de ameaças, brigas, intimidações ou qualquer outra modalidade de confronto, envolvendo não só os alunos como também os professores "colocam a escola sob um clima psicológico ameaçador a ponto de levar seus atores a um estado de alerta permanente [...] integram o cotidiano da escola, solicitando uma vigilância constante dos profissionais" (MARRA e TOSTA, 2008, p. 176).

De acordo com Teixeira e Porto (1998), essa dificuldade crescente de exercer a autoridade, de utilizar medidas pedagógicas que venham a reduzir as ações antiéticas e ilegais no seu interior, leva o professor a considerar que tais atribuições não sejam exclusivamente suas, admitindo a possibilidade de recorrer a outros "olhares" que permitam tornar tais tarefas menos árduas. Com isso, percebe-se cada vez mais a dificuldade de que a resolução de conflitos em sala de aula seja tratada pedagogicamente.

Muito embora a utilização de câmeras de vigilância nos espaços escolares busque prioritariamente reduzir os atos de violência, criando um ambiente mais seguro para os ocupantes deste espaço, admite-se também que a presença deste equipamento possa funcionar como instrumento que faz coibir atos de indisciplina dos alunos.

Rennó e Boschetti (2011) ao relatarem a importância que os aparatos de vigilância eletrônica representam para a segurança daqueles que frequentam o espaço escolar, também frisam que a utilização desses mesmos equipamentos de vigilância se assemelha ao funcionamento do dispositivo panóptico, uma vez que, através de seu olhar constante, permite exercer a função de controle disciplinar. Para os autores,

grande parte das escolas, atualmente, considera indispensável usar de dispositivos de segurança e contenção. A partir dos recursos disponíveis 
à instituição escolar, o uso vai das grades de ferro [...] da vigilância externa e monitoramento 24 horas, à ronda policial. Portanto, a vigilância na escola, usada em nome da segurança, é uma constante, e pode ser considerada como um viés norteador do poder disciplinar, tomada como algo que deve ser contínuo, presente em todos os espaços da escola. A função dos equipamentos pode ser comparada com a ideia do panóptico, presumindo o olhar vigilante ao menor sinal de transgressão, relacionadas não só à conduta de alunos, mas, significativamente, à conduta de professores; exercendo assim uma função controladora de tudo e de todos (Rennó e Boschetti,2011, p. 04-05).

Machado (1993) afirma que a presença da câmera de vigilância faz com que o indivíduo desenvolva uma preocupação com o seu comportamento, procurando adequar suas ações com as normas estabelecidas pela instituição de ensino. A auto vigilância leva o indivíduo a não praticar uma ação considerada inadequada às normas da escola, evitando-se, assim, possíveis punições.

Batista (2013), ao se referir especificamente às câmeras de vigilância utilizadas como circuito fechado de tevês, expõe que os entusiastas dessa tecnologia consideram que o uso desse instrumento além de representar uma busca utópica de um ambiente seguro, pode levar a distopia de um controle absoluto das condutas das pessoas.

De acordo com Guimarães (2003), as câmeras de vigilância contribuem para o adestramento dos alunos, evitando a ocorrência de atos de indisciplina. A simples presença da câmera pode ser capaz de modificar o comportamento dos vigiados, adequando suas ações às normas existentes nas unidades de ensino a que pertencem. Mesmo raciocínio é compartilhado por Rennó e Boschetti (2011), ao relatar que as câmeras representam os instrumentos utilizados para captar os menores sinais de transgressão no ambiente escolar, sejam não só envolvendo o comportamento dos alunos, mas incluindo também a conduta dos professores.

Assim, ao adotar uma vigilância constante sobre as ações dos indivíduos, a escola procura estabelecer um padrão ideal de atitudes com o objetivo de evitar que as indisciplinas se transformem em armas contra as estruturas já estabelecidas. Dessa forma, podemos afirmar que "uma espécie de modulação de práticas e ações RC: 35932

Disponível em: https://www.nucleodoconhecimento.com.br/educacao/vigilancia-eletronica 
cotidianas também são produzidas e/ou intensificadas como efeito de um espaço intensamente vigiado" (CASTRO e PEDRO, 2010, p.36).

Ratto (2007) afirma que a escola demonstra uma necessidade de praticar uma vigilância constante, objetivando exercer um controle rígido e extensivo das ações que acontecem no seu cotidiano. Para a autora, a ausência do olhar vigilante representa um dos grandes "fantasmas" da indisciplina. (RATTO, 2007).

Dessa forma, os modernos dispositivos de vigilância eletrônica podem apresentar um poder de ação similar ao do dispositivo panóptico, ou seja, desencadear uma autovigilância que culmina na reforma, na interiorização do indivíduo, pois o olhar do outro faz com que o próprio indivíduo passe a observar suas próprias ações, seus próprios comportamentos. (FOUCAULT, 2014).

Melgaço (2012) também destaca essa função que as câmeras de vigilância possuem de disciplinar os alunos no espaço escolar. A presença destes equipamentos no ambiente escolar não se justifica apenas pelo desejo de reduzir atos de violência, mas pela sua capacidade de tornar os indivíduos mais disciplinados e promover um controle generalizado dos comportamentos. Para o autor, "as câmeras colocadas dentro das classes não têm exatamente a função de garantir a segurança dos alunos de um risco externo, mas são voltadas a disciplinar o comportamento dos estudantes e dos professores" (MELGAÇO, 2012, p. 201).

\section{SALA DE AULA: A PRIVACIDADE EM TEMPOS DE NOVAS TECNOLOGIAS DE VIGILÂNCIA}

Diante da crescente invasão dos equipamentos de vigilância eletrônica no cotidiano das pessoas, tem-se discutido muito a necessidade de conferir maior proteção à vida privada, direito fundamental da personalidade humana. Embora garantido constitucionalmente, o direito à privacidade vem sendo cada vez mais difícil de ser resguardado e respeitado.

Especialistas na área ${ }^{[3]}$ entendem que a violação deste princípio interfere nas relações pessoais, modificando os modos de agir e pensar, inibindo o poder de criação e obstruindo o processo de comunicação envolvendo o indivíduo e sociedade. Sendo 
assim, as formas solidárias de relacionamento entre as pessoas, como a confiança e a cooperação espontânea, encontram-se completamente prejudicadas em nossa sociedade (BAUMAN, 2014).

Quando se trata de espaço escolar, especificamente a sala de aula, acredita-se que a exposição de professores e alunos a uma constante vigilância possa comprometer o desenvolvimento de um trabalho autônomo, contrariando o direito à intimidade e à privacidade. A constante incidência do foco de visibilidade sobre alunos e professores representa, de acordo com argumentos de representantes de profissionais em educação ${ }^{[4]}$, um instrumento nocivo ao processo de ensino e aprendizagem, uma vez que inibe a manifestação de ideias e limita a liberdade de ação.

Existe, com isso, o entendimento de que o monitoramento em tempo real de professores e alunos possa ocasionar a perda da espontaneidade necessária na formação dos sujeitos, interferindo na construção de uma relação onde as verdades sejam manifestadas de forma plena. A presença da câmera de vigilância em sala de aula gera uma situação que contribui para desconstruir uma relação de respeito, de confiança mútua, estabelecida entre alunos e educadores, resultando em uma mudança de relacionamento entre os indivíduos.

No entanto, as novas tecnologias associadas às práticas de vigilância se agigantaram e tomaram novas dimensões, tornando-se uma característica onipresente da sociedade. Com o passar dos anos o cidadão comum, onde quer que esteja, torna-se alvo constante de monitoramento por uma gama de recursos tecnológicos cada vez mais sofisticados.

Atualmente, aqueles que se encontram no interior dos espaços escolares também estão sujeitos aos olhares intimidadores das novas tecnologias de vigilância. Multiplicando-se em uma progressão geométrica, a realidade nos mostra que tais dispositivos, antes encontradas do lado de fora das escolas, estão invadindo também esse ambiente, projetando cada vez mais seus olhares técnicos e impessoais a professores e estudantes não só quando se encontram no espaço escolar, ou até mesmo fora deste. 
Essa dinâmica da contemporaneidade vem relativizar o direito a privacidade $e$, segundo especialistas do tema, o transforma em um dos maiores problemas deste século. Nesse aspecto, mesmo diante dessa banalização da exposição, "questões como anonimato, confidencialidade e privacidade não devem ser ignoradas" (BAUMAN, 2014, p.20).

Ao citar o fenômeno de propagação da vigilância, resultando no crescimento significativo de espaços públicos vigiados, Batista (2013) alerta para o fato de que o alto nível de aceitação deste tipo de vigilância em alguns espaços públicos, como bancos, estações de transportes urbanos, centros comerciais e outros demonstram certa passividade das pessoas no que se refere à invasão de privacidade. $\mathrm{O}$ que se pode esperar é que os indivíduos não mais se surpreendam com o processo de vigilância contínua, tratando-o como uma prática justificável e aceitável.

Batista (2013) alerta para o fato de que, como vivemos em uma sociedade cada vez mais interconectada, o direito de "ficar sozinho" não tem mais sentido nos dias de hoje. Para a autora, o entendimento de privacidade enquanto possuidora da dicotomia entre o público e o privado está chegando ao fim. Ainda de acordo com a autora, essa separação que existe entre o público e o privado está desaparecendo em decorrência do crescente processo de individualismo e privatização dos espaços.

Nesse aspecto, vale ressaltar que atualmente existe uma verdadeira erosão da privacidade, que é resultado não somente de uma grande variedade de produtos de vigilância eletrônica disponíveis no mercado, mas, principalmente, de uma mudança na visão dos indivíduos no que tange ao entendimento de espaços público e privado (BAUMAN, 2014, p. 29).

Percebemos, diante disso, a existência de um conflito entre o que se considera um espaço público e um espaço privado. De acordo com Bruno (2004), novas formas de exposições diante das câmeras abalam as fronteiras entre o público e o privado, desencadeando uma crise de limites entre eles. Hoje, comportamentos que para muitos possam ser considerados um ato privado, passam a ser expostos publicamente de maneira voluntária. 
Embora nos dias atuais seja admitida uma inexistência da privacidade diante da presença onipresente de instrumentos de vigilância, deve-se levar em conta que, especificamente no espaço escolar, essa intromissão talvez não represente uma ameaça que venha a prejudicar o trabalho do profissional de educação. Nesse sentido, há de se levar em consideração que

nos dias de hoje, o que nos assusta não é tanto a possibilidade de violação da privacidade, mas o oposto, o fechamento das saídas. A área da privacidade transforma-se num lugar de encerramento, sendo o dono do espaço privado condenado e sentenciado a padecer expiando os próprios erros; forçado a uma condição marcada pela ausência de ouvintes ávidos por extrair e remover os segredos que se ocultam por trás das trincheiras da privacidade, por exibi-los publicamente e tornálos propriedade comum de todos, que todos desejam compartilhar. Parece que não sentimos nenhum prazer em ter segredos (BAUMAN,2014, p.34).

Pensamento semelhante é exposto por Sousa (2013), quando trata do interesse que determinados sujeitos manifestam de expor suas atividades pessoais, pensamentos e atitudes. Tais pessoas, ao fazer de suas qualidades e de seus defeitos verdadeiros atrativos para que aqueles que os observam, acabam desenvolvendo relações sociais. Ao citar Moran (2001), o autor defende que

faremos com as tecnologias mais avançadas o mesmo que fazemos conosco, com os outros, com a vida. Se somos pessoas abertas, iremos utilizá-las para nos comunicarmos mais, para interagirmos melhor [...] o poder de interação não está fundamentalmente na tecnologias, mas nas nossas mentes (MORAN, 2001, p. 63, apud SOUSA, 2013, p.26).

Lyon (2010) ressalta que o motivo das pessoas se deixarem ser observadas equiparase com o motivo daquelas que desejam observar. Esse comportamento é atribuído a um sentimento denominado pelo autor de escopofilia, ou seja, uma necessidade neurótica de vigiar ou amor de observar áreas da vida consideradas inacessíveis ou estritamente privadas. 
Talvez, possamos ter nesse sentimento uma maneira de justificar uma certa facilidade na implantação de dispositivos de vigilância, seja nos espaços públicos ou privados, sem confrontar com resistência daqueles que irão ficar na condição de vigiados. O autor considera que

a escopofilia parece ter-se tornado culturalmente central em tempos pósmodernos, o que ajuda a explicar melhor porque empresas e governos não encontram dificuldades para vender e instalar tecnologias de vigilância[...]o oposto do amor por observar os outros, que é o amor por ser observado, significa novamente que muitos não se importam em serem vigiados (LYON, 2010, p.138).

O desejo do indivíduo em mostrar suas ações que até então se limitavam ao âmbito privado, como pelo desejo das pessoas em observar tais ações. Essa dupla combinação consolida o que Firmino (2010) chama de "sociedade espectadora" e favorece com que ocorra uma aceitação das pessoas em se deixarem ser vigiadas pelos equipamentos de vigilância.

a vigilância - que em sua raiz social e etimológica está ligada à observação - é aceita facilmente porque vários tipos de observação tornaram-se comuns em uma sociedade espectadora [...] à medida que coisas antes consideradas privadas tornam-se abertas ao olhar público de muitos, e à medida que certas áreas íntimas e reclusas da vida são vasculhadas, parece ser cada vez menos importante que este ou aquele dado pessoal, certa vez protegido, esteja agora disponível (FIRMINO, 2010, p.117).

Neste ambiente de vigilância onipresente, Guimarães (2003) chama a atenção para a existência do comportamento de neutralidade dos indivíduos, especialmente no espaço escolar. Estando já acostumados com a constante presença das câmeras, os alunos já não se mostram mais intimidados com seu olhar vigilante. Para a autora, tais alunos simplesmente ignoram a presença destes dispositivos de vigilância eletrônica.

Rennó (2009), também considera que, com o passar do tempo, é comum as pessoas se acostumarem com as câmeras e ignorarem a sua presença, agindo com 
indiferença. Segundo a autora, o poder coercitivo é mais evidente no período imediatamente posterior à instalação desses aparelhos. Após esse período, as pessoas agiriam com neutralidade diante a presença da câmera de vigilância, inclusive quando utilizada no ambiente escolar.

\section{CONSIDERAÇÕES FINAIS}

Atos de violência são uma realidade nos espaços escolares, incluindo, entre estes, as salas de aula. Neste atual cenário, é gerado um clima de insegurança que compromete as ações de professores e alunos. Objetivando maior segurança nestes espaços, e com isso, dar a continuidade normal do processo de ensino e aprendizagem, tem-se recorrido à implantação de dispositivos de vigilância eletrônica.

A presença destes dispositivos pode coibir novos atos de violência ou servir como instrumento que auxilie na resolução de conflitos violentos ocorridos. Entretanto, diante também do cenário de indisciplina generalizada que assola o ambiente escolar, considera-se também a possibilidade de a simples presença desse instrumento representar um meio de disciplinar as ações de alunos e professores naquele espaço.

A mudança de comportamento possivelmente advinda com a implantação de câmeras nas salas de aula demonstra que os modernos dispositivos de vigilância eletrônica apresentam um poder de ação similar ao do dispositivo panóptico, por desencadearem um processo de interiorização dos vigiados. Tais instrumentos estimulam a autovigilância, pois o olhar do outro faz com que o próprio indivíduo passe a observar a si mesmo, seus atos, seus comportamentos. Essa ação no aspecto psicológico altera, por conseguinte, as relações sociais e práticas pedagógicas ocorridas nestes espaços.

Com relação à perda da privacidade que, ao longo dos anos, vem sendo utilizada como justificativa para não aceitação das instalações de câmeras nos interiores das salas, cabe alertar que tal motivo, possivelmente, não se mostre suficientemente forte para impedir a utilização dessa tecnologia de vigilância diante os frequentes atos de violência praticados nestes espaços. 
Certamente, a possibilidade de utilizar dispositivos de vigilância eletrônica no interior das salas de aula não represente, hoje, o mesmo incômodo causado anos atrás. A forte propagação que as tecnologias de vigilância vêm tendo nos últimos anos faz relativizar constantemente o conceito entre público e privado. Indivíduos, inseridos em uma "sociedade do espetáculo", passam a expor suas ações voluntariamente. Ao contrário do que muitos argumentam o olhar vigilante da câmera, em vez de inibir ações dos daqueles que se encontram na condição de vigiados, pode ser capaz de levar os indivíduos a exibirem seus atos ou comportar-se com neutralidade.

Entendemos que discutir essa questão é uma forma de contribuir nas decisões a serem tomadas pela comunidade escolar e gestores públicos no tocante a utilização ou não da vigilância eletrônica para demais unidades de ensino. Evita-se, assim, que sejam tomadas medidas arbitrárias, sem conhecimento prévio das opiniões de educadores e educandos, o que poderia gerar insatisfações e constrangimentos em toda a comunidade escolar.

Tratando-se de uma ferramenta com capacidade de transformar as ações de professores e alunos no espaço escolar, de forma a influenciar no processo de ensino e aprendizagem, cabe a cada unidade de ensino promover a discussão de forma democrática e participativa, objetivando tomar a decisão mais adequada à realidade em que se encontra inserida. Permite-se, assim, utilizar o instrumento de vigilância e, sobretudo, suas imagens geradas, de forma racional.

Há de se ressaltar que os posicionamentos aqui expostos a respeito deste tema não possuem caráter definitivo. As tecnologias de vigilância estão em um processo dinâmico de construção e de inserção na sociedade, e também no ambiente escolar. Concomitante ao seu processo de introdução, opiniões vão sendo também construídas a respeito dos benefícios e danos que podem causar à população escolar, contribuindo para a tomada de decisão de forma mais acertada. Vale lembrar que por se tratar de um dispositivo ainda em franco debate, tal instrumento fica sujeito a diferentes opiniões e questionamentos.

\section{REFERÊNCIAS}


ABRAMOVAY, Miriam; AVANCINI, Marta; OLIVEIRA, Helena. Violência nas Escolas. O Bê-a-Bá da Intolerância e da Discriminação. Disponível em: https://www.unicef.org/brazil/pt/Cap_02.pdf. Acesso: 20/04/2017

ARAÚJO, Jeferson Santos.- Esboço Sobre o Surgimento, as Características, e a Implantação do Método Monitorial/Mútuo no Brasil do Século XIX.Cadernos da Pedagogia. São Carlos, 4 v. 4 n. 7, p. 86 - 95. Ano: 2010.

BATISTA, Marcela de Moraes. Muito Além da Vigilância Eletrônica: Um Estudo Acerca do Discurso Governamental do Centro de Comando de Controle Integrado de Pernambuco.Universidade Federal de Pernambuco - Programa de Pós-Graduação em Administração. Recife/PE.Ano:2013. Disponível em https://repositorio.ufpe.br/handle/123456789/10987. Acesso em 18/06/2017.

BAUMAN, Zygmunt. Vigilância Líquida. Ed. Zahar. Rio de janeiro/RJ. Ano: 2014. . O Mal-Estar na Pós-Modernidade. Rio de Janeiro/RJ: Ed. Zahar. Ano: 1998.

BRUNO, Fernanda. Máquinas de Ver, Modos de Ser: Visibilidade e Subjetividade nas Novas Tecnologias de Informação e de Comunicação. Revista da FAMECOS,v. 24, p. 110 - 124. Porto Alegre/RS. Ano: 2004.

CASTRO, Rafael Barreto; PEDRO, Rosa Maria Leite Ribeiro. Redes de Vigilância: A Experiência da Segurança e da Visibilidade Articuladas às Câmeras de Monitoramento Urbano. In: Vigilância e Visibilidade: Espaço, Tecnologia e Identificação. Ed. Sulina. Porto Alegre/RS. Ano: 2010.

FIRMINO, Rodrigo; DUARTE, Fábio. Espaço, Visibilidade e Tecnologias: (Re)caracterizando a Experiência Urbana. In: Vigilância e Visibilidade: Espaço, Tecnologia e Identificação. Ed. Sulina. Porto Alegre/RS. Ano: 2010.

FOUCAULT, Michel. Vigiar e Punir:Nascimento da Prisão. 42 ed. Ed. Vozes. Petrópolis/ RJ. Ano: 2014. 
GUIMARÃES, Áurea Maria. Vigilância, Punição e Depredação Escolar. $3^{a}$ ed. Papirus Editora. Campinas/SP. Ano: 2003.

LEMOS, André. Mídias Locativas e Vigilância. Sujeito Inseguro, Bolhas Digitais, Paredes Virtuais e Territórios Informacionais. In: Vigilância e Visibilidade: Espaço, Tecnologia e Identificação. Ed. Sulina. Porto Alegre/RS. Ano: 2010

LYON, David. 11 De Setembro, Sinóptico e Escopofilia: Observando e Sendo Observado. In: Vigilância e Visibilidade: Espaço, Tecnologia e Identificação. Ed. Sulina. Porto Alegre / RS. Ano: 2010.

MACHADO, Arlindo. Máquinas de Vigiar.Revista USP, (7), 23-32. Disponível em https://doi.org/10.11606/issn.2316-9036.v0i7p23-32. São Paulo. Ano: 1993. Acesso em 19/09/2017

MARRA, Célia Auxiliadora dos Santos; TOSTA, Sandra Pereira. Violência Escolar: Percepção e Repercussão no Cotidiano da Escola.In: A Síndrome do Medo Contemporâneo e a Violência na Escola. Autêntica Editora. Belo Horizonte/MG. Ano: 2008

Melgaço, Lucas.Estudantes Sob Controle: a Racionalização do Espaço Escolar Através do Uso de Câmeras de Vigilância - Revista O Social em Questão - Ano XV no $27-2012$.

RATTO, Ana Lucia Silva. Disciplina, Vigilância e Pedagogia. Cadernos de Pesquisa, v. 37, n. 131, maio/ago. 2007. Disponível em http://www.scielo.br/pdf/cp/v37n131/a1237131.pdf. Acesso em 17/03/2017.

RENNÓ, Claudia Martins Ribeiro. A complexidade entre a disciplina e a vigilância na escola. III Encontro De Pesquisa Discente -Programa De Pós-Graduação Em Educação Da Uninove. Dez./2009.

RENNÓ, Claudia Martins Ribeiro; BOSCHETTI, Vânia Regina.Disciplinamento nas Instituições Escolares: Uma Prática Histórica Permanente.In: VI Congresso Brasileiro de História da Educação - UFES.Vitória - ES. Ano: 2011. Disponível em 
www.fisic.org/disciplinamento-nas-instituicoes-escolares-uma-pratica historica.html. Acesso 26/02/2017

ROCHA, Gilmar. "Complexo de Emílio". Da Violência na Escola à Síndrome do Medo Contemporâneo. In: A Síndrome do Medo Contemporâneo e a Violência na Escola. Autêntica Editora. Belo Horizonte/MG. Ano: 2008.

SILVA, Luciano Campos; NOGUEIRA, Maria Alice. Indisciplina ou Violência na Escola? Uma Distinção Possível e Necessária. In: A Síndrome do Medo Contemporâneo e a Violência na Escola. Autêntica Editora. Belo Horizonte/MG. Ano: 2008

SOUSA, Luciano Dias. O Comportamento Social Entre o Público e Privado na Era Digital.Revista Ícone Revista de Divulgação Científica em Língua Portuguesa, Linguística e Literatura.Volume 12 - Agosto/ 2013 - ISSN 1982-7717. Disponivel em https://www.revista.ueg.br/index.php/icone/article/view/5024. Acesso: 22/05/2017.

TEIXEIRA, Maria Cecilia Sanches; PORTO, Maria do Rosario Silveira. Violência, Insegurança e Imaginário do Medo.Cad. CEDES [online]. 1998, vol.19, n.47, pp. 5166. ISSN 1678-7110.

2. Pesquisa Nacional Sobre Violência, Aids e Drogas nas Escolas, que resultou no livro Violência nas Escolas, 1 publicado em 2002 pela Organização das Nações Unidas para a Educação, a Ciência e a Cultura (UNESCO). Disponível em: http://www.unicef.org/brazil/pt/Cap_02.pdf

3. VIEIRA, Alexandre Pires; RALVES, Jose Claudio. O Direito à Privacidade Frente aos Avanços Tecnológicos na Sociedade da Informação. Disponível em: https://jus.com.br/artigos/27972.

4. Stefanoski, Celso Floriano. O Uso de Câmeras de Vigilância em Sala de Aula. Disponível em https://www.sinprors.org.br/comunicacao/noticias.

Enviado: Maio, 2019.

Aprovado: Agosto, 2019. 